\title{
El uso de las piedras de corte en los monumentos y en la construcción. 1. Areniscas y calizas
}

\author{
PUCHE RIART, O.; GARCIA DE MIGUEL, J. M.; SANCHEZ CASTILLO, L; MATA PERELLO, J. M., \\ y GONZALEZ AGUADO, M. T. \\ Cátedra de Mineralogía. Escuela Técnica Superior de Ingenieros de Minas. MADRID
}

\begin{abstract}
Fecha de recepción: $16-X-90$
\end{abstract}
\section{RESUMEN}

Se describen diversas variedades de areniscas y calizas no pulimentadas empleadas habitualmente en la costrucción, indicando en que terrenos aparecen y como se deterioran.

\section{RESUME}

On a effectué la description de différentes variétées de grés et de roches calcaires non poulies employées habituellement dans la construction, en indiquant les terrains dans lesquels ils apparaisent ainsi que leurs altérations.

\section{INTRODUCCIÓN}

Existen numerosas piedras de corte empleadas en construcción a las que se ha prestado poca atención científica, esto tal vez sea debido a su menor interés económico dentro del sector, pero podemos asegurar que muestran una importancia sustancial a nivel local y monumental, tal es el caso de calizas de no muy buen pulimento, areniscas, cuarcitas, rocas volcánicas y otras muchas especies de carácter dispar.

A través de nuestros estudios de las piedras naturales en edificaciones monumentales, hemos llegado a preguntas de difícil respuesta sobre el origen de los materiales presentes; esto nos ha llevado a inventariar numerosas canteras españolas y formaciones geológicas susceptibles de mostrar niveles explotables, labor en la que estamos inmersos, dando así respuesta, en los casos de restauración de monumentos, a la necesaria sustitución de piezas pétreas muy deterioradas y de las que se desconoce su procedencia con exactitud.

A principios de siglo, ya decía D. PEDRO NOVO, Catedrático de Geología de la Escuela de Ingenieros de Minas de Madrid, "que cuando fuésemos de viaje, al llegar a una población, lo primero a realizar debería ser efectuar una visita a la iglesia: para dar gracias a Dios por haber llegado sin percance al destino previsto, así como para comprobar la fábrica pétrea de la misma y mediante nuestros conocimientos escolares deducir la geología del entorno". 
Realmente, los pueblos son un reflejo de su substrato rocoso; casas y monumentos se han levantado con los elementos pétreos presentes. Así vemos poblados negros sobre las lavas basálticas de las Islas Afortunadas, poblados rojizos sobre las facies continentales del Trias, poblados grises sobre las areniscas carboníferas y poblados blancos sobre las calizas del páramo castellano. Por otro lado la piedra útil es la que determina la estructura arquitectónica del país, así como el aspecto externo y modo constructivo de sus edificaciones, existiendo una clara relación entre Geología y Arquitectura.

\section{VARIEDADES DE ARENISCAS Y CUARCITAS EMPLEADAS EN CONSTRUCCIÓN}

Hay una serie de propiedades a tener en cuenta respecto a la utilización de estas rocas en la construcción, tal es el caso de la resistencia mecánica a la compresión, dureza, alterabilidad y otros.

La resistencia a la compresión de areniscas y cuarcitas varía dentro de un amplio margen, oscilando entre menos de 100 y más de $1.800 \mathrm{~kg} / \mathrm{cm}^{2}$. Este valor depende esencialmente de los componentes mineralógicos de la roca, así como de su distribución y de los procesos geológicos sufridos por la misma (compactación, cementación, metamorfismo, etc.).

Las areniscas de cemento silíceo y las cuarcitas son las rocas que presentan una mayor resistencia a la compresión, pero por otro lado, son también las que muestran mayor resistencia al corte, lo que en muchos casos condiciona su empleo.

La cuarcita es buena para mampostería, pero no se puede labrar, restringiéndose su uso para la fabricación de adoquines y la construcción de muros rústicos. Por lo general, es una roca de uso local a lo largo de todo el Macizo Hespérico.

Son innumerables las pequeñas canteras abandonadas que se asientan sobre las barras de areniscas prehercínicas, con cemento silíceo, aflorantes en las proximidades de los pueblos del Oeste peninsular, al igual que ocurre en el Macizo Armoricano francés. Por poner algún ejemplo de construcción con estas rocas citaremos: El castillo de Alarcos, en Ciudad Real, edificado con cuarcitas del Arenig, la muralla de Almadenejes, en la misma provincia, realizada con cuarcitas del Siluriano ("Cuarcita del Criadero"), o el castillo de Falaise, en Francia, construido con "cuarcitas armoricanas". Asimismo, en este último país, se han utilizado los materiales antes mencionados como pavimento, por ejemplo los adoquines elaborados con cuarcitas terciarias de Fontainebleau, sobre todo los de Ybette, y en numerosas ocasiones los fabricados con cuarcitas ordovícicas.

En España existen pocas explotaciones activas de cuarcitas, siendo de mayor importancia las de la Comunidad de Castilla y León.

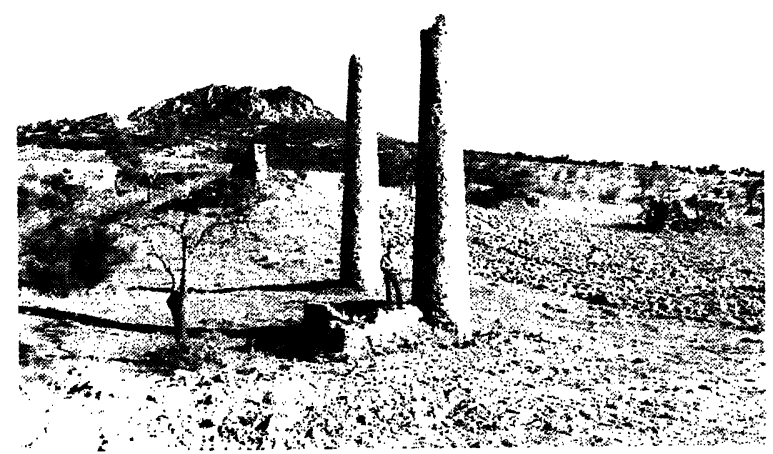

Foto 1.-Chimeneas de los hornos de la mina del Quinto del Hierro (Ciudad Real), construidas con cuarzitas paleozoicas.

Las areniscas de cemento carbonatado son, en ocasiones auténticas calcarenitas, a veces algo arcillosas, y en algunas regiones reciben la denominación de "maciño". Estas rocas son duras, compactas, y por lo general permeables, lo que impide su aplicación en zócalos así como cimentaciones, ya que suelen provocar problemas de ascenso capilar, responsables de humedades, con lo que se incrementa la alteración de la roca. En España se presentan en el Albense, abundan mucho en las facies flysch del Eoceno de Euskadi-Pirineos, donde se han explotado para las construcciones monumentales del País Vasco, y también se muestran en otros Sistemas como el Mioceno Superior, tal es el caso de algunas de las explotaciones del Cerro San Cristóbal, en el Puerto de Sta. María.

Por otro lado, existen rocas denominadas "molasas". Este término obedece a un origen tectónico, sin embargo su etimología hace referencia a propiedades litológicas, discutiéndose si el origen de esta palabra se debe a "muela", por su utilización como piedras de molino, o a "mollis", que en latín significa blando. En la Cuenca del Ródano, donde nació el término, y en Suiza, abundan las areniscas de grano grosero que se acogen a esta denominación, son blancas, verdosas (debido a la presencia de glauconita), o rojizas y en ellas el cemento calcáreo suele formar hasta un tercio de la roca. Son piedras ligeras, de fácil talla y buena resistencia. Como ejemplo de su aplicación en construcción, citaremos la murallas de Carcassone, en Francia.

En el caso de las areniscas de matriz arcillosa, cuando su cemento las dota de suficiente resistencia a la compresión, se emplean como piedra de construcción. Estas rocas son ligeras, de fácil talla y poca permeabilidad original, presentando el inconveniente de su alterabilidad y disgregación, debido al incremento de volumen en las esmectitas (minerales arcillosos) que unen los granos silíceos de la roca. Según MARTIN GARCIA, J. C. y MARTIN GARCIA, M. A. (1966) estas rocas muestran nombres variados, en distintas partes de la geografía española: asperillo (zona de Jerez-Gibraltar), tallaide (Cartagena) y otros. Abundan sobre todo en terrenos cenozoicos. 
Las areniscas micáferas reciben la denominación de "samitas", sobre todo cuando son un poco arcillosas. En ellas son frecuentes las disyunciones paralepipédicas de origen tectónico, denominadas en Alemania "quadersandstein", ya que dichas diaclasas son apreciables en algunas areniscas cretácicas de Sajonia. Estas fracturas fueron aprovechadas por los canteros de Narros (Soria), enseñados por artesanos gallegos, para seleccionar las piezas de menor trabajo en el corte.

Las areniscas de cemento ferruginoso, al igual que en los últimos casos, si la pasta de unión dota a la roca de suficiente resistencia, pueden utilizarse en construcción. En muchos casos, estas rocas muestran un color rojo-vinoso típico de las facies continentales. En España son muy frecuentes, situación lógica al alcanzar el Trías gran extensión. En Castellón y Valencia, a esta roca se le denomina "rodeno". Como ejemplo de empleo de las areniscas ferruginosas en construcción se puede citar el conjunto monumental de Medinaceli (Soria).

En Francia abundan unas rocas similares a las anteriores, donde al cemento ferruginoso se suma la presencia de materia orgánica, constituyendo la variedad denominada "pierre de l'Alios" que se caracteriza por sus tonos marrones o negros. Son muy típicas las explotaciones de estos materiales bajo las arenas de las Landas y en la zona de París.

Las areniscas arcósicas son malas rocas de construcción porque a la larga se produce la caolinización del feldespato presente. En Avila monumental, se han empleado mucho unas areniscas grises neógenas de este tipo, extrayéndose piedra para la restauración de la ciudad en el cerro de la Colilla, a dos o tres kilómetros del casco urbano, habiéndose creado una reserva de terreno subsceptible de explotación en cantera para este fin a favor de la Diputación Provincial.

Las grauwacas son areniscas no silíceas, de color oscuro, abundante cemento, ricas en clorita y minerales arcillosos, conteniendo granos de cuarzo y feldespato, algunas mica y restos de rocas de grano fino de origen magmático básico o esquistoso. Generalmente son rocas compactas, duras y poco permeables, empleándose en las construcciones locales así como en la pavimentación de calles. Abundan en las series precámbricas y paleozoicas del Oeste Peninsular.

Existen otras rocas detríticas, que sin pertenecer a las familias de las areniscas o las cuarcitas se emplean en construcción con carácter local; tal es el caso de las brechas neógenas con cemento ferruginoso utilizadas en la edificación de las viviendas de la zona del Negredo-Becerril (Segovia), los conglomerados paleógenos de Espejón (Soria), utilizados en la ciudad romana de Clunia (como roca ornamental también aparecen en la Catedral del Burgo de Osma y en el Palacio de Oriente), así como otras variedades de brechas y pudingas.

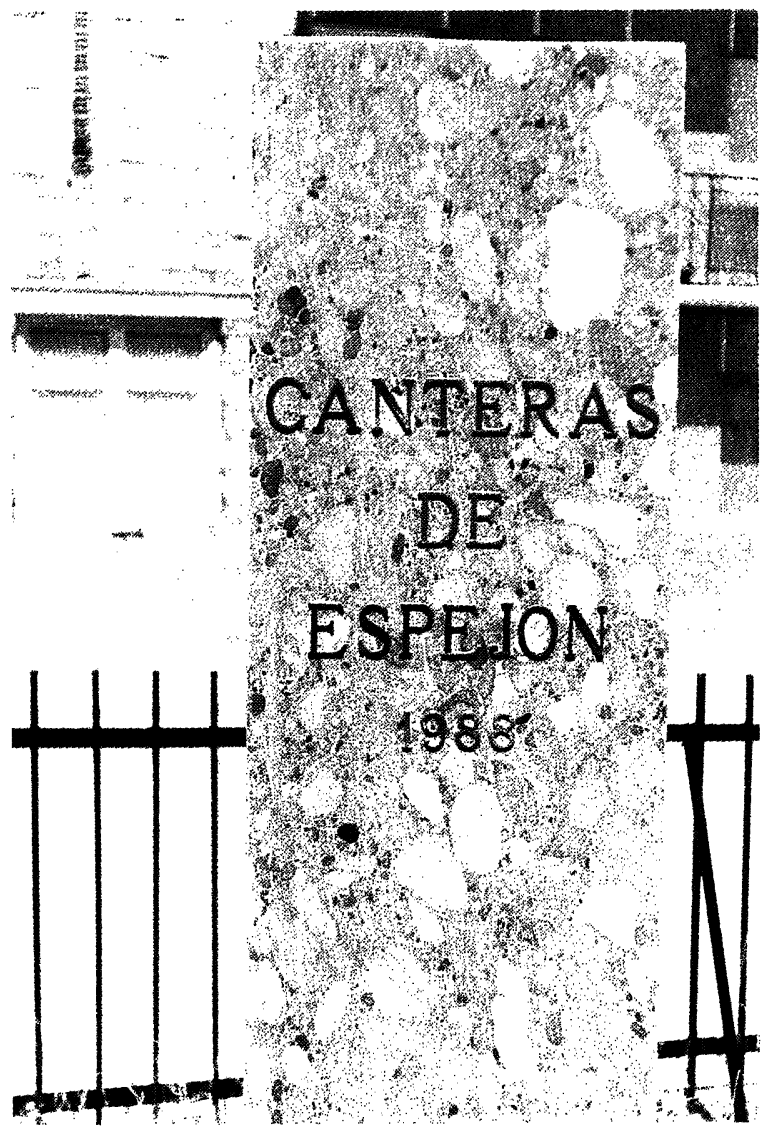

Foto 2.-Conglomerado carbonatado de las "facies Garum" utilizado como roca ornamental.

Otras rocas a tener en cuenta, fuera también del grupo considerado, pero con un fuerte contenido en sílice son las generadas por la acción de geles silíceos sobre calizas porosas y cuyo aspecto es similar al de las piedras molares descritas con anterioridad. Estos materiales son ligeros, de gran resistencia a la compresión y poca permeabilidad, siendo ideales en cimentaciones, situación muy frecuente en la ciudad de París, en cuyos alrededores se conocen numerosas localidades con canteras de este material: Montmorency, Mont-Valérien, Meudon y otras.

\section{YACIMIENTOS DE ARENICAS EMPLEADAS EN CONSTRUCCIÓN}

Las areniscas precámbricas y paleozoicas no muestran un gran desarrollo en el sector de la construcción, salvo la "new red sandstone", del Rothliegendes (Permiano), pese a que en España carece de interés. La llamada "Arenisca de Los Vosgos", pertenece a este Sistema, siendo una roca rojiza con la que se han edificado las catedrales de los bordes del Rhin: Estrasburgo, Bâle, etc.

En España, las principales canteras aparecen con el Mesozoico. Destacamos las ubicadas sobre las areniscas abigarradas del Buntsandstein, en el Piso 


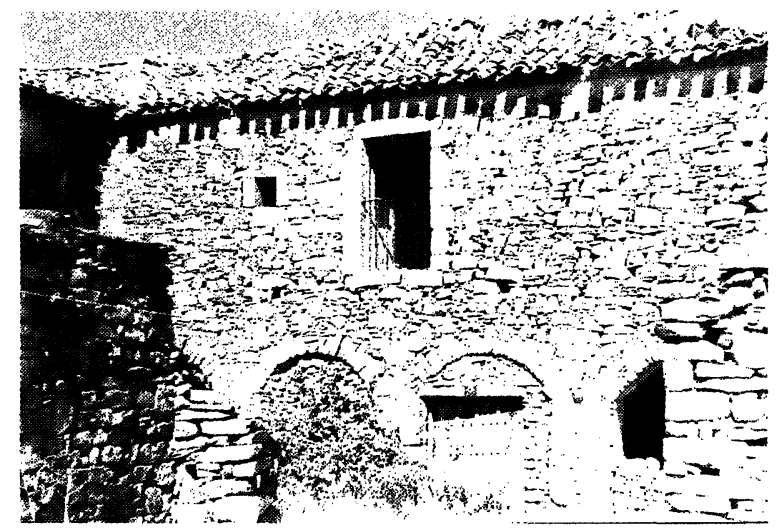

Foto 3.-Construcción rural en Suellacabras (Soria) a base de areniscas y alguna caliza del Jurásico.

inferior del Sistema Triásico, y como ejemplo de ello podemos citar las de San Feliú de Condinas (Barcelona), las de San Millán de la Cogolla o las de Fuenmayor en La Rioja, situándose en ésta última localidad una escuela de canteros, en la que se trata de perpetuar las nobles tradiciones del arte de trabajar la piedra.

En la parte superior del Malm (Jurásico) se presentan unas areniscas abigarradas, de origen deltaico, formando parte de las facies Purbeck. En Asturias constituyen una serie denominada "Areniscas de Ribadesella", con canteras en diversos lugares, tales como Somió y Tazones. Con estas últimas se han construido algunos monumentos en Gijón, como es el caso del Palacio de Revillagigedo. También se extraen areniscas jurásicas en la Aldehuela de Periáñez (Soria), para la restauración de algunos monumentos del dicha capital.

Según PIÑERO, A. en el Cretáceo inferior tenemos la facies continentales del Weald, donde asientan numerosas explotaciones, por ejemplo las areniscas y calcarenitas de Villaroya, en La Rioja, y Mosqueruela en el Maestrazgo.

Tras la transgresión cretácea aparecen los depósitos del Albense, con sus características arenas, en algunas zonas areniscas, de colores claros. Los principales afloramientos se sitúan en la Cadena lbérica, siendo numerosas las canteras ubicadas en la provincia de Soria y zonas limítrofes, tal y como se puede comprobar en Palacios de la Sierra (Burgos).

Ya en la Era Terciaria, aparecen numerosas explotaciones en las facies lacustres del Eoceno y del Oligoceno. Dentro de los materiales areniscosos explotados en estos Sistemas mencionaremos la "Piedra Folgueroles", arcosa extraída de las canteras eocenas próximas a la población de Osona (Barcelona), con la que se han edificado el Seminario y la Catedral de Vich, así como el Monumento a Mosén Jacinto Verdaguer, en Barcelona. Así mismo, hay que resaltar la "Piedra de Villamayor", en Salamanca, la cual podríamos definir como arenisca eocénica-oligocénica, de color claro, con cambios laterales de tono y minerales ferruginosos, los cuales al alterarse dan los tonos dorados típicos de los monumentos y viviendas salmantinas. Por último, indicar que en Haro (La Rioja) se explotan areniscas de la Formación Haro, las cuales constituyen las fachadas y claustros de numerosos monumentos riojanos.

Así mismo, citaremos las areniscas del Mioceno lacustre, aflorantes en la cuesta de las "Calizas del Páramo", cuyos granos aparecen unidos con cemento carbonatado, pero que sólo se han explotado con carácter local. Podemos apreciar su aplicación en muros rústicos, como por ejemplo ocurre en algunos del casco histórico de Alcalá de Henares.

También son miocenas las areniscas silíceas de origen marino de Montjuic, con la que se han construído algunas partes del Ayuntamiento de Barcelona y el escudo del Palacio de La Ciudadela. Estas rocas en algunas zonas se muestran como auténticas lumaquelas, plagadas de Turritellas.

Por último, citaremos las areniscas consolidadas del Cuaternario, poco abundantes, pero algunas tan peculiares como las dunas fósiles del Levante español.

\section{ALTERACION DE LAS ARENISCAS}

Las areniscas fuertemente arcillosas o margosas absorben el agua con facilidad, de acuerdo con mecanismos capilares (gran porosidad atrapada), por lo que se ablandan, se hinchan y sufren con mayor intensidad la acción del hielo, desmoronándose. En algunos sitios, tales como la Plaza Mayor de Salamanca, han solucionado el problema mediante el empleo de zócalos de granito, roca más impermeable (si no se encuentra fisurada), colocando la "Arenisca de Villamayor" a partir de una cierta altura, ya libre de las humedades ascendentes.

Las areniscas calcáreas son susceptibles de alterarse mediante la polución, problema importante en los tiempos actuales. El ácido sulfúrico, formado a partir de los gases de combustión, diluido en el agua de lluvia, penetra en la roca atacando al carbonato y provocando finalmente la formación de cristales de yeso en las zonas más superficiales.

Las areniscas arcósicas sufren una alteración típica y de gran intensidad, consistente en la hidrolización de los feldespatos a sericita o caolín según el clima y la naturaleza del mineral, con la consiguiente pérdida de cohesión y resistencia mecánica.

En algunos casos, como ocurre en las areniscas silíceas de Montjuic (Barcelona), aparecen cristales idiomorfos de pirita $\left(\mathrm{FeS}_{2}\right)$ provocando cambios cromáticos en la roca. La piedra original en fractura fresca, es de color azul, pero a corto plazo tras su exposición al ambiente oxidante del medio externo se produce una limonitización del sulfuro, adquirien- 
do la roca un color amarillento. Las piritas se descomponen con rapidez, formándose no sólo limonita, sino también sulfato de hierro y ácido sulfúrico. Si el cemento de la roca fuese calizo o dolomítico podría formarse yeso o sulfato de magnesio. Más peligrosas son la marcasita $\left(\mathrm{FeS}_{2}\right)$ y la pirrotina ( $\mathrm{FeS}$ ) ya que se alteran todavía con mayor facilidad que la pirita.

Las areniscas de colores grises y negros, debidos a la presencia de materia orgánica, en contacto con la atmósfera pueden ver su color aclarado por oxidación de las sustancias carbonosas.

No se puede hablar de alteraciones sin considerar que en muchos casos el restaurador piensa que se encuentra ante un proceso de degradación responsable de un cromatismo específico, o de una costra de ennegrecimiento generada por la polución, cuando en definitiva lo que se tiene es una pátina de recubrimiento artificial de la roca, realizado por nuestros antepasados con fines estéticos y de protección. En consecuencia, se debe ser extremadamente cuidadoso a la hora de eliminar las partes más externas de la roca, ya que las técnicas de recubrimiento que se emplearon en la antigüedad han mostrado una gran eficacia, preservando de su destrucción, el material, a lo largo del tiempo.

La elección del método de limpieza de un determinado material debe atenerse a lo anteriormente citado, evitando en todo lo posible la utilización de productos fuertemente agresivos. Del mismo modo el restaurador deberá tener en cuenta la naturaleza petrológica de la roca. Por ejemplo una arenisca con presencia de hierro como mineral accesorio al ser limpiada con ácido clorhídrico puede dar lugar al amarilleamiento de la piedra.

Otras veces, la alteración puede ser consecuencia del mismo inadecuado proceso de tratamiento para la consolidación o hidrofugación. Por ejemplo, el silicato de etilo deposita un gel de sílice que en cantidades excesivas puede traducirse en antiestéticos blanqueamientos de la roca tratada.

\section{CALIZAS Y OTRAS ROCAS CARBONATADAS EMPLEADAS EN LA CONSTRUCCION}

Por lo general las calizas y demás rocas carbonatadas muestran una menor resistencia a la compresión que las areniscas. Para comprobar lo anterior pondremos varios ejemplos: las calizas tiernas aguantan de 20 a $100 \mathrm{~kg} / \mathrm{cm}^{2}$, las calizas oolíticas del jurásico entre 150 y $225 \mathrm{~kg} / \mathrm{cm}^{2}$, y las variedades ya metamorfizadas (los mármoles) entre 700 y $1.200 \mathrm{~kg} / \mathrm{cm}^{2}$, algunas incluso más.

Las rocas carbonatadas, debido a la baja dureza de la calcita (su principal componente) se cortan con facilidad en comparación con aquellas rocas, como muchas areniscas, con cuarzo relativamente abundante. Otra ventaja es su baja densidad, de valor medio próximo a $2 \mathrm{gr} / \mathrm{cm}^{3}$.
Las variedades más compactas se utilizan en sillería, mampostería, solados, bordillos y plaquetas. Las tobas y otras piedras toscas se utilizan en las partes altas de los edificios, por conjugarse su ligereza con alta resistencia a la compresión, así como por adherirse los morteros con facilidad a su superficie porosa, ejemplo de ello podemos observar en la construcción de las bóvedas de la Catedral de León, donde estas piedras han sido colocadas por su bajo peso específi$c 0$, olvidándose de su posible permeabilidad al quedar protegidas por la cubierta.

En los bordillos y solados el desgaste es rápido, pese a ello se usan para este fin allí donde la proximidad a las canteras o las condiciones de mercado, $e$ incluso la estética, lo han impuesto. Por ejemplo, en la Plaza Mayor de Torrejón de Ardoz, o en los bordillos de las calles de Colmenar de Oreja (Madrid) y de Olvega (Soria).

A continuación se describirán algunas variedades de calizas empleadas en la construcción; se comenzarán enumerando las variedades alóctonas para pasar seguidamente a las autóctonas.

Los conglomerados calcáreos, constituidos por cantos rodados de calizas preexistentes, en general, no se pueden utilizar en sillería ya que se rompen con facilidad, debido a su heterogeneidad, aunque las variedades marmóreas sí suelen presentar interés ornamental por sus propiedades estéticas.

Las calcarenitas son calizas formadas por pequeños gránulos rodados procedentes de la destrucción de rocas similares preexistentes, las cuales suelen venir acompañadas por cantidades variables de detritos cuarzosos, siempre en proporción inferior al $50 \%$. Si el contenido en cuarzo es suficiente, a veces estas rocas muestran una apariencia de areniscas. Un ejemplo típico de ellas es la denominada "Piedra de Bateig" que se explota en la zona de Novelda, o la "Piedra de Almorquí", de Casas del Señor, ambas aflorantes en potentes bancos del Mioceno marino de la provincia de Alicante.

La "Piedra de Novelda" es una calcarenita beig, amarillenta o azulada que se ha empleado con profusión desde el siglo pasado, por ejemplo, podríamos citar: la Escuela de Minas de Madrid, la Estación del Norte - construida con la variedad azul-, el Ministerio de Hacienda en la calle de Alcalá, los monumentos a Alfonso XII e Isabel II, la sede de la Compañia Telefónica Nacional, el Monumento a Colón, el Palacio de Linares, partes renovadas del Ayuntamiento de Sevilla y del Palacio de Santa Cruz. Con la "Piedra de Almorquí" se han construido partes de la Catedral de la Almudena y se ha restaurado la fachada de la Antigua Universidad de Alcalá de Henares.

Muchas veces estas rocas, además de cuarzo llevan arcillas, con los consiguientes problemas de alterabilidad que esto conlleva. 
Las calizas conchífera, también llamadas coquinas - lumaquelas, se han empleado con piedra de corte desde antiguo. Están formadas por conchas y caparazones de diversos organismos, principalmente moluscos, braquiópodos y foraminíferos, así como crinoides y equinodermos.

Los egipcios recubrieron la pirámide de Micerinos con calizas numulíticas del Eoceno, las cuales al meteorizarse liberaron los fósiles que contenían; esto llevó a Plinio a indicar que "...alrededor de ella sólo hay arena cuyos granos son como lentejas...". También son calizas numulíticas las que se han explotado en los alrededores de Gerona y con las que se ha construido la Catedral y buena parte de los monumentos de dicha ciudad, así como el Monasterio de Gallicanto.

Otras calizas conchíferas son las denominadas calizas de Miliólidos conteniendo innumerables esqueletos de foraminíferos, con un diámetro máximo de $1 \mathrm{~mm}$. Son excelentes piedras de sillería, abundando mucho en terrenos del Paleogeno de la región prepidinaica y del Cretáceo.

Otra variedad la constituyen las calizas de Cerithium, formadas por conchas de gasterópodos o en muchos casos por sus moldes externos, ya que aquéllas fueron disueltas por las aguas de infiltración. Son malas piedras de sillería debido a su carácter tosco, pero se usan en mampostería o en placas, las cuales luego son revestidas por cemento o mortero para evitar el paso de las aguas. Estas rocas son muy típicas de los terrenos terciarios (Eoceno) de la cuenca del Marne, en Francia, habiéndose explotado en Vaugirad, Creil, Chantilly y otras localidades francesas. Resaltamos el hecho de ser la piedra de construcción por excelencia en la región de París, tal y como ocurre en buena parte del Louvre, la capilla de Versalles o en zonas de Nôtre-Dame.

También hay que considerar a las calizas de troquites, o placas columnares que forma el tallo de los crinoides, las cuales suelen encontrarse sueltas formando en ocasiones notables aglomeraciones, tal como podemos apreciar en el Cobleciense de Arnao (Devoniano de Asturias); las calizas de Rudistas, aflorantes en la península de la Magdalena (Santander) donde destacan las conchas de Tucasias; las calizas con espículas de equínidos; las calizas coralígenas, abundantes en el Cretácico; la "Piedra Ostrionera" del Plioceno Superior de Puerto Real (Cádiz) rica en ostras y pectínidos, con la que se han edificado numerosos monumentos de la capital de la provincia; y tantas otras variedades.

Las calizas oolíticas se forman por la unión de granos subesféricos de calcita, dispuestos en capas concéntricas, constituidas por precipitación química alrededor de un grano de arena o un trozo de concha. Abunda mucho en el Jurásico y, dentro de este Sistema, principalmente en el Dogger, aunque también las hay en el Malm. Una variedad de esta roca, de color amarillento, es la denominada "Pie-

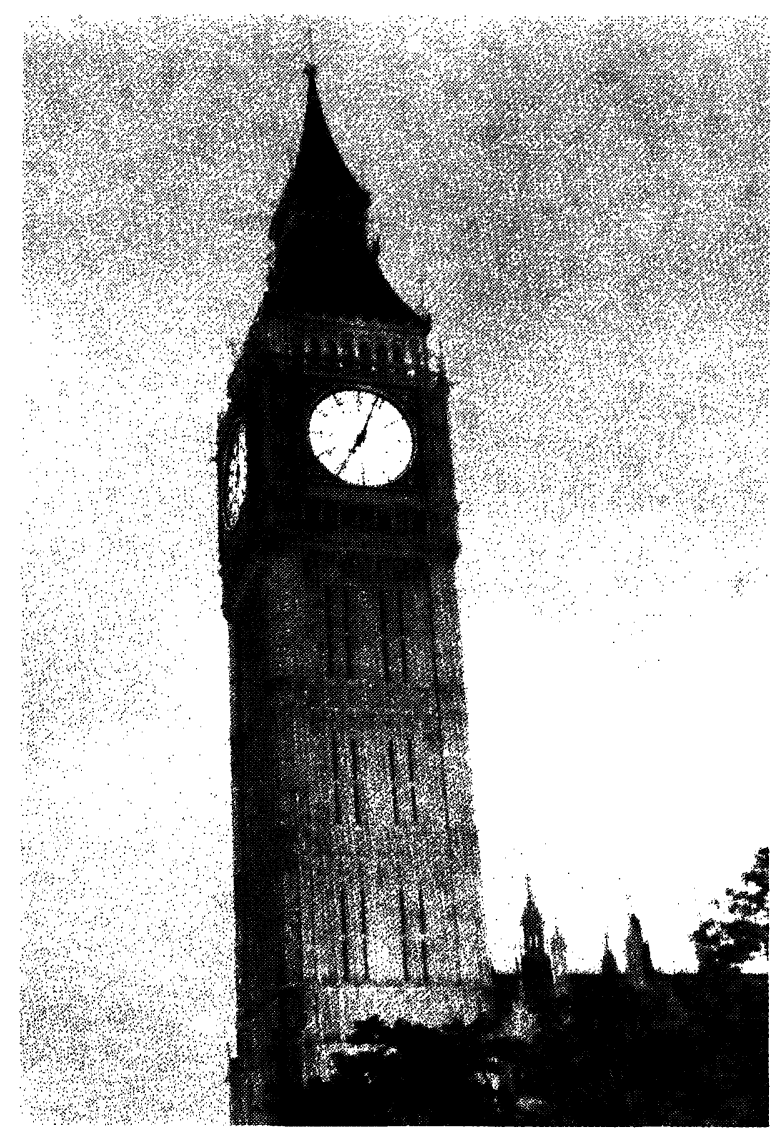

Foto 4.-"Piedra de Caén", caliza oolítica del batoniense. Torre del parlamente Británico.

dra de Caén", del Bathoniense, la cual suele ser suficientemente blanda como para poder ser cortada con facilidad. Esta piedra no solo puede observarse en la Catedral de Caén, sino que aparece en la mayor parte de las iglesias de Normandia, habiéndose exportado con profusión a la Gran Bretaña, donde es frecuente verla formando parte de los monumentos londinenses tales como: Westminster, Catedral de Canterbury y otros. Asimismo, es muy típico su empleo en las construcciones rurales en las zonas del Jura y de Lyon. En España merece la pena mencionar las calizas jurásticas, de color blanco cremoso, con posible procedencia de Gilena, empleadas en la construcción de algunos lugares de la Catedral de Sevilla y las calizas de Santany, de Mallorca, empleadas en la construcción de la Catedral de Palma y en otros monumentos de la Isla. Esta última es una caliza blanca que por alteración adquiere un color teja claro, es fosilífera, muy porosa y de fácil corte, explotándose en terrenos del Mioceno Superior.

La creta, es una roca sedimentaria marina, de grano muy fino y blanda, se disgrega fácilmente con los dedos y es muy porosa, estando buena parte de ella, por lo general, formada por caparazones de foraminíferos plactónicos mesozoicos. Por las propiedades descritas se deduce que es una mala piedra de construcción, ya que es muy friable $y$ 


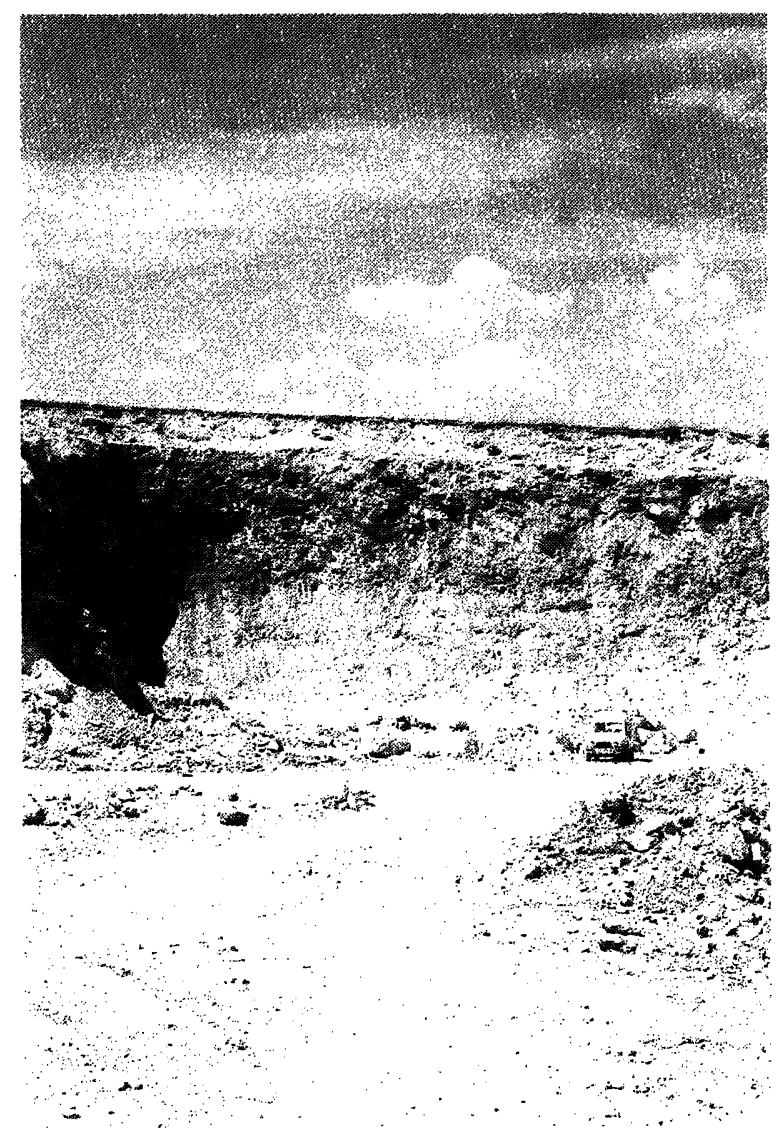

Foto 5.-Canteras de "Piedra de Colmenar", calizas del Pontiense, en Colmenar de Oreja (Madrid).

sensible a las heladas, pese a ello se ha empleado en algunos interiores, tal y como podemos apreciar en el coro de la Catedral de Beubais.

Las tobas se originan por la precipitación química en capas concéntricas del carbonato sobre vegetales subacuáticos. Cuando desaparece la materia orgánica queda una roca compacta, ligera y porosa. Estas rocas se incluyen dentro del grupo de "piedras toscas" de las que ya se han descrito sus propiedades y aplicaciones.

Las calizas lacustres y los travertinos se producen por precipitación química de $\mathrm{CO}_{3} \mathrm{Ca}$, en aguas dulces ricas en bicarbonato cálcico. Se caracterizan por su grano de tamaño fino y, en general, por sus colores claros, mostrando frecuentemente un aspecto concrecional, una cierta proporción de vacuolas y estratificación grosera. Las vacuolas son debidas, en parte, a la desaparición de restos vegetales por fermentación, siendo rellenados estos huecos, en algunos casos, por calcita espática; dicha estructura se traduce en una mala capacidad de ser pulidas y en una buena adherencia al mortero. Tanto el grano de tamaño fino, como su baja dureza, posibilitan una fácil talla, la que ha configurado a esta variedad como soporte de muchos trabajos cuidadosos, así como en la fabricación de esculturas. Se puede citar al respecto el travertino de Sézanne que fue labrado por Munier-Chalmas.
Travertino tiene su origen en el toponímico Tivertino, población próxima a Roma, siendo dicha variedad la principal piedra de construcción en la capital de Italia; con ella se han edificado entre otros monumentos, las murallas, el Colisio, y San Pedro Vaticano. Los romanos ya empleaban esta roca con profusión y de ella decía PLINIO "...soportan sin daño lo mismo cargas muy pesadas que condiciones climática muy duras. Ahora bien, no pueden resistir el fuego, porque se rompen y abren inmediatamente..." En Alemania existen importantes yacimientos en Constadt, cerca de Stuttgard, $y$ en Rasdorf, cerca de Göttingen. En Francia existen numerosas variedades de travertino, a destacar la "Piedra de Château-Landon", del Oligoceno, con la que se han construido diversos monumentos parisinos, tales como el Arco de Triunfo, la Basílica de Montmartre, la Universidad de la Sorbonne, etc.

En España se han explotado calizas lacustres en numerosas localidades: Agreda (Soria), Albox y Alhama (Almería), Campaspero (Valladolid), Colmenar de Oreja (Madrid), Ocaña (Toledo), Bañolas (Gerona) y muchos otros lugares. Mención particular hay que hacer de la "Piedra de Colmenar", que junto con la granítica "Piedra Berroqueña" de la Sierra de Guadarrama, constituyen diversos elementos de buena parte de los monumentos madrileños, por citar algunos: Palacio de Oriente, Plaza Mayor de Madrid, Catedral de la Almudena, Palacio de Aranjuez, Jardín Botánico, Plaza Mayor de Torrejón de Ardoz, Plaza Mayor de Chinchón, etc.

Las calizas margosas son carbonatos de cal con una cierta fracción arcillosa, que aparecen con profusión en el Cretácico. Son buenas piedras de construcción, empleándose mucho en el Norte de España.

Las dolomías son rocas carbonatadas, con cierta proporción de dolomita mezclada con calcita, y con un origen dispar: Unas veces se forman por precipitación química en un medio lacustre, otras se producen por alteración de las calizas ante la acción de lejías magnesianas. En ambos casos, estas rocas suelen ser más resistentes a la erosión que las calizas y algo más duras, aunque no mucho, lo que en algún caso las ha convertido en buenas piedras de talla, tal y como es el caso de la dolomía de Boñar, sobre la que se han labrado las partes más delicadas de la catedral de León. La "Piedra de Boñar", también se presenta en el parador de S. Marcos y en la iglesia de S. Isidro de León, así como en numerosos monumentos del Camino de Santiago. Asimismo, algunas dolomías cuarzosas del Jurásico se han empleado como adoquines.

No se abordará aquí el estudio de los "mármoles", en su más amplio concepto, debido a que suelen encontrar más aplicación como roca ornamental que como material de construcción, existiendo numerosos trabajos $\theta$ inventarios sobre rocas pulimentadas; solamente conviene indicar la exis- 


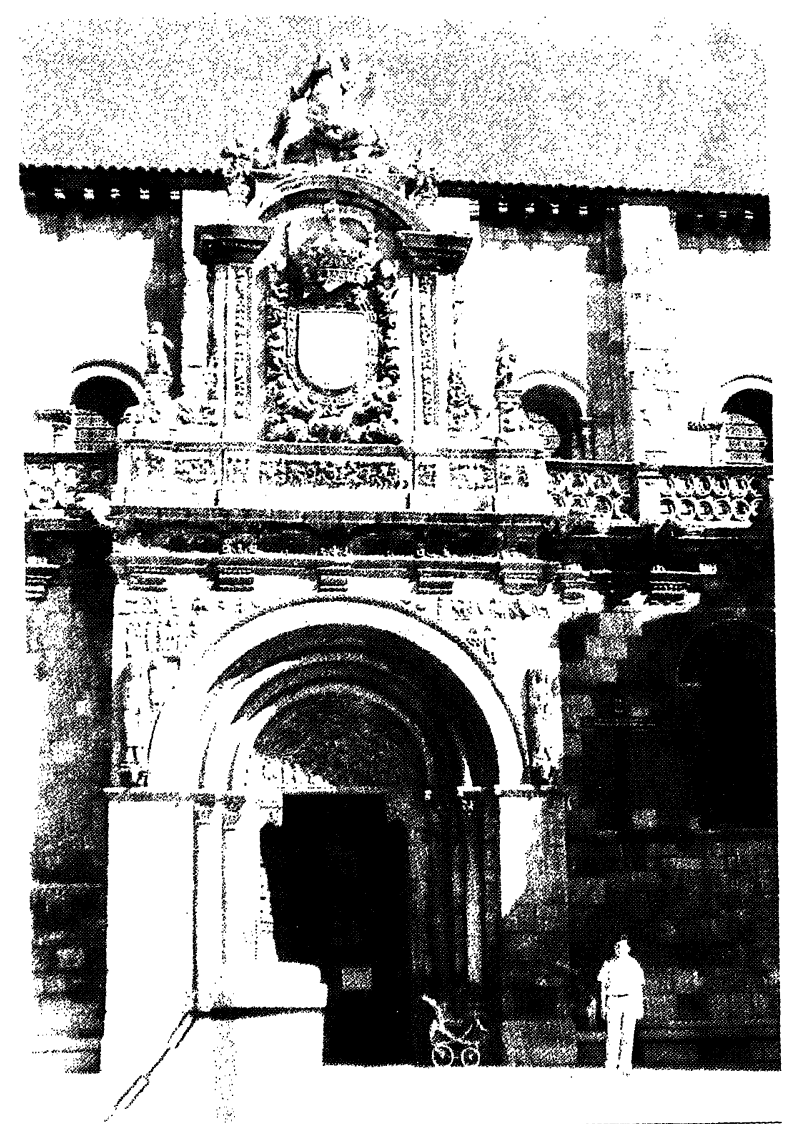

Foto 6.- Tallas elaboradas con dolomías de Boñar, Parador de San Marcos, en León.

tencia de rocas calizas que vienen siendo utilizadas en ambos sentidos.

\section{YACIMIENTOS DE ROCAS CARBONATADAS}

Las calizas precambrianas, son generalmente oscuras, no suelen mostrar grandes espesores y aparecen muy tectonizadas como para generar grandes explotaciones, sin embargo muestran aplicaciones en la construcción de viviendas rurales del Macizo Hespérico y en algún caso excepcional como piedra de talla, por ejemplo: la pila bautismal de la cárcel de forzados de Almadén (Ciudad Real), recogida en el Museo Histórico-Minero Francisco Pablo Holgado, de la Universidad de Castilla-La Mancha.

Lo mismo es posible afirmar de las calizas cambrianas, algunas de las cuales se pueden observar en la Catedral de Toledo, procedentes de la zona de San Pablo de los Montes.

En Francia, las calizas del Devoniano y del Carbonífero del Noroeste, en concreto las de la zona de Givet, se han explotado durante mucho tiempo como piedra de construcción. En España las "calizas de montaña" del Carbonífero Inferior se han aplicado en diversos edificios de Oviedo, tales como el Palacio del Principado y las iglesias de San
Juan y San Pedro de: los: Arcos, existiend $q$ canteras de estas rocas en La Manjoya, Villaperez y otros lugares de Asturias..

Las formaciones geológicas del Mesozoico al no haber sido afectadas por las orogenias antealpinas, muestran una menor fracturación, sim que, en la mayor parte de la Península Ibérica, ed! metamorfismo regional deje sentir sus efectos. Debido a ello, frecuentemente presentan mayores zonas subceptibles de ser explotadas en canteras como rocas de corte.

En el Trías "germánico", aparecen calizas conchíferas en el Muschelkalk, tal y como pocemos apreciar en la parte oriental de la Península lbérica. En el Trías "alpino" se encuentran calizas y dolomías, de "facies recifales", tal y como es posible comprobar en las Cadenas Béticas. El límite de Trías viene definido por la presencia de carniolas y calizas cavernosas de origen evaporítico. En este Sistema las principales explotaciones se presentan en las calizas del Muschellkalk, las cuales en algunos casos no muestran una excesiva fracturación, tal y como ocurre en las proximidades de Alhama de Aragón (Guadalajara), donde es posible la extracción de bloques de gran tamaño, utilizadas para escolleras de presa y muros de gran tamaño.

El Jurásico es un Sistema con gran predominio de rocas carbonatadas. En el Lías abundan las calizas, dolomías y carniolas, las cuales se explotan en numerosos lugares, tales como Torremocha del Pinar (Guadalajara), la Sierra de Cabra (Córdoba) - Buenhache de la Sierra (Cuenca), en este último yacimiento se utilizan para la producción de terrazos. También son jurásicas las calizas negras de Ricla y Calatorao (Zaragoza). De esta zona ha salido buena parte de la piedra monumental de Aragón, así como los Evangelistas del Valle de los Caídos, o parte del pavimento de la Plaza de la Armería del Palacio Real. En esta última zona, en la actualidad quedan algunas canteras activas con explotaciones artesanas de bordillos. Del DoggerMalm son también las calizas oolíticas de Gilena (Sevilla).

En el Cretaceo inferior aparecen importantes formaciones de calizas arrecifales y en el Cretaceo superior hay un predominio de los niveles carbonatados, algunos de los cuales están formados por las siguientes rocas: "Caliza Piedramuelle" del Este astuariano, empleada en la Catedral de Oviedo; caliza bioclástica rosada de Sepúlveda, usada para la construcción de la Catedral de Segovia o en partes del Palacio de Oriente; "Piedra de Tamajón" y calizas dolomíticas de El Vellón (seguramente extraídas de la histórica cantera de Onzerruecas en la provincia de Madrid), abundantemente utilzadas en la construcción monumental en Alcalá de Henares; "Dolomía de Boñar" (León); "Piedra de Bascuña de S. Pedro" (Cuenca), usada en terrazos; y tantas otras. 
En líneas generales este Sistema alcanza un buen desarrollo en Santander y Vascongadas, así como en Pirineos y la lbérica.

En el Paleógeno también abundan las calizas entre otras las numulíticas. Probablemente sean de esta época las calizas dolomíticas del Cerro de la Rosa (Toledo), con las que se han construido el Monasterio de Sta. Cruz, San Juan de los Reyes y la parte antigua de la Catedral de Toledo. Con la "Piedra de Laspra", del Eoceno-Oligoceno, del Alto del Cristo, cerca de Oviedo, se han edificado partes de Sta. M. a del Naranco, San Miguel de Lillo y la Catedral de Oviedo. También es eocena la caliza de $\mathrm{S}$. Vicente de Castellet (Barcelona), piedra monumental de la zona de Manresa. Y por último es obligado citar la "Piedra de Floresta", dolomita calcárea, con la que se ha edificado la Seo (Lérida) y los Monasterios de Poblet y de Les Santes Creus.

En el Neógeno es donde se encuentra el mayor número de canteras de rocas de construcción, en lo que a España concierne. Respecto a las facies continentales merece la pena destacar las cuencas endorreicas de las dos Castillas y la depresión del Ebro (Mioceno lacustre). En lo que se refiere a las facies marinas, las zonas más importantes son las de Alcoy (Plioceno de Alicante) así como la cuenca del Guadalquivir.

Las calizas lacustres miocenas se denominan "Calizas de Páramo" y se han extraído en Campaspero (Valladolid), siendo utilizadas en la construcción de la Catedral, Universidad, e iglesias de Sta. M. de la Antigua, San Pablo y San Gregorio, dentro de Valladolid. En Castilla-León, también conviene mencionar la caliza oquerosa de Palacios del Alcor, mientras que en Castilla-La Mancha se pueden citar las de Colmenar de Oreja (Madrid) y Ocaña (Toledo). Del travertino de Bañolas (Gerona), se puede indicar su origen plioceno.

En el Mioceno Marino de la cuenca de Alcoy, abundan las calcarenitas. Aparte de la "Piedra de Bateig" y la "Piedra de Almorquí" ya mencionadas,

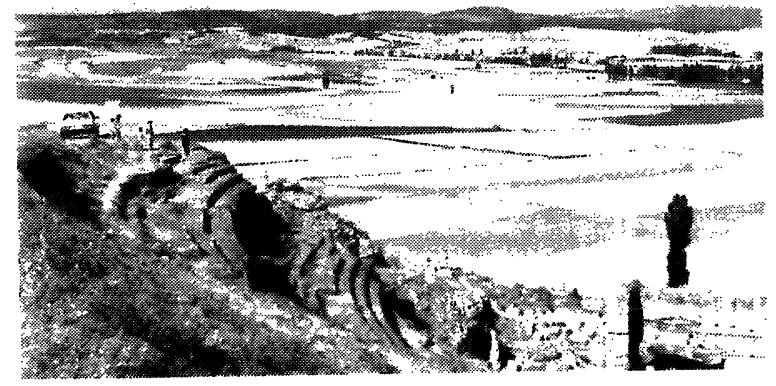

Foto 7.-Anfiteatro de la ciudad romana de Clunia, excavado sobre las calizas del páramo del Mioceno lacustre de la cuenca castellano-leonesa.

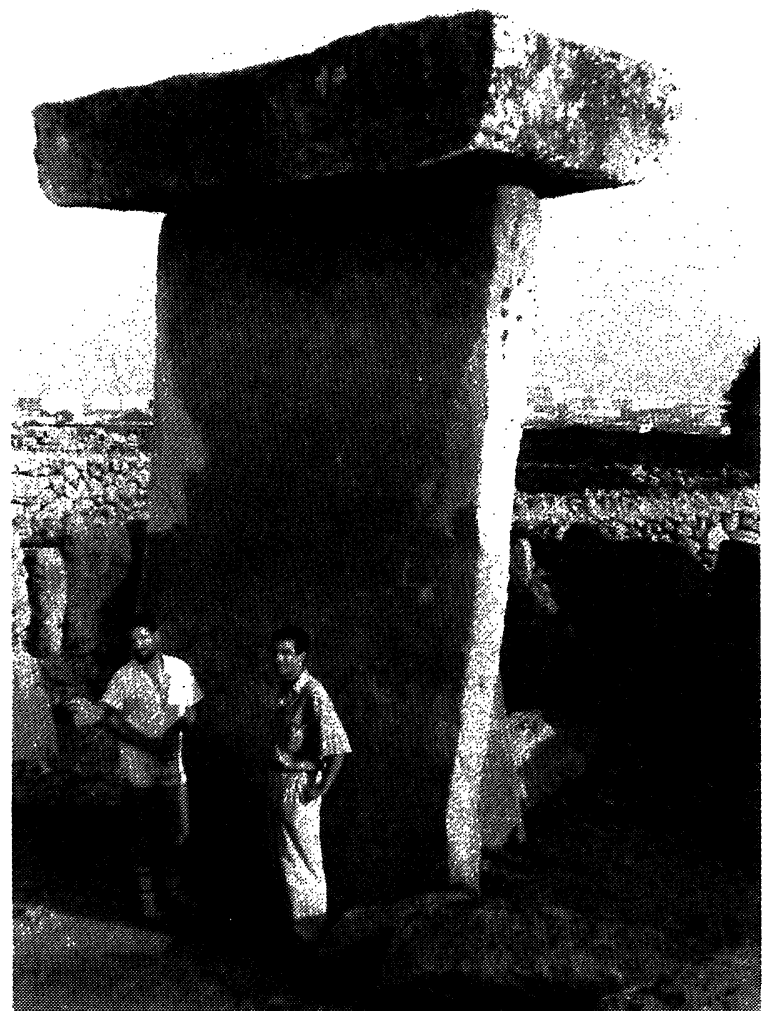

Foto 8.--"Taulas" de Menorca, construidas con "marés".

hay que hacer referencia a la "Piedra de Petrel" (Alicante), con la que se ha construido la fachada del edificio de Correos, y la cantera de la Sierra del Caballo (Alicante), donde se ha extraído piedra para la construcción del Banco de España. Para esta última edificación también se ha utilizado la calcarenita de Abarán (Murcia).

En la cuenca del Guadalquivir, son importantes las calcarenitas del Andaluciense (Mioceno Superior). Estos materiales se han extraído en la zona de Jerez de la Frontera, Cerro de S. Cristóbal en el Pto. de Santa María, Mairena de Alcor, Utrera y Espera, y utilizado en la Catedral de Sevilla, así como las de Carmona y Alcalá de Guadaira, empleadas en construcción y restauración.

En el Mioceno marino de Baleares también se han extraído calcarenitas denominatas "marés", empleadas con profusión en la isla de Menorca para cimentaciones, paramentos y tabiques. En Mallorca, "marés", es una caliza de granos tamaño arena unidos por cemento calcáreo, explotada en el Cuaternario de la zona del. Arenal y otros lugares.

\section{ALTERABILIDAD DE LAS ROCAS CARBONATA- DAS}

La caliza es una roca formada fundamentalmente por carbonatos. Los carbonatos son muy suscepti 


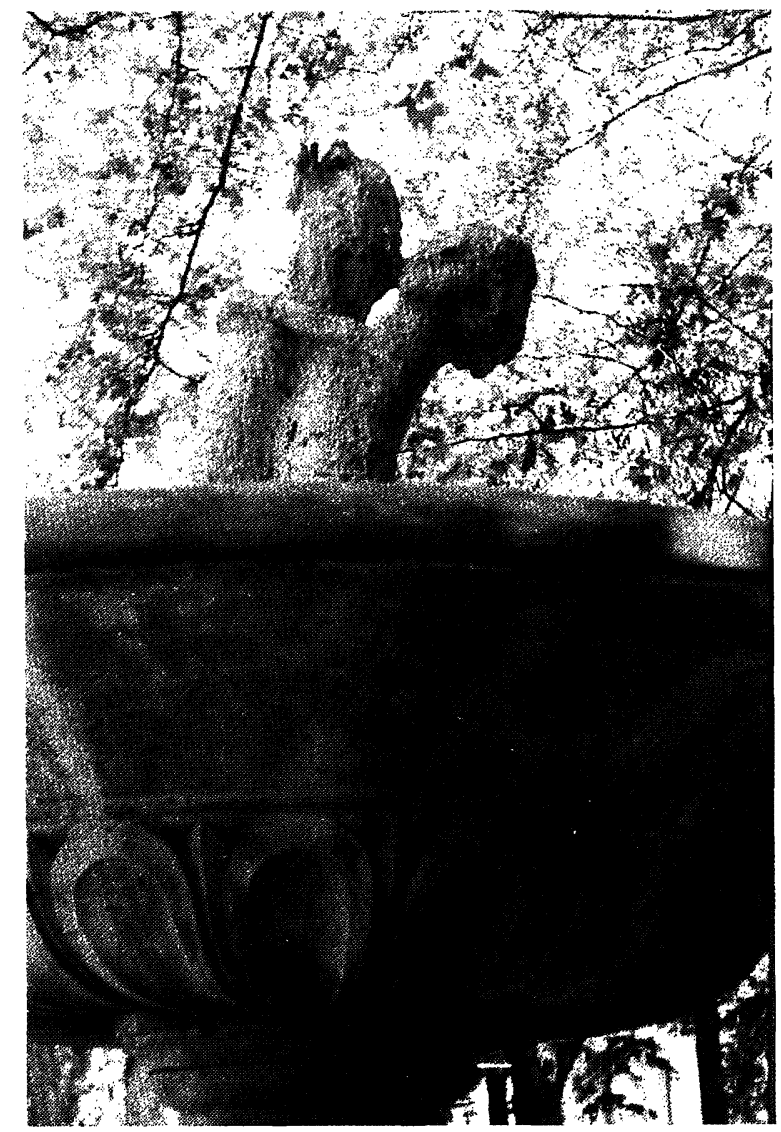

Foto 9.-Procesos de karstificación en una fuente del Paseo del Prado por efecto de la contaminación urbana.

bles de ataque químico en medio ácido, por consiguiente, la roca caliza se disuelve por acción de las aguas con bajo $\mathrm{pH}$. La acidez puede deberse al contenido en $\mathrm{CO}_{2} \mathrm{O}$ a otras causas. El resultado es, finalmente, la eliminación de relieves en las tallas y esculturas constituyendo, este proceso, en ocasiones, en una auténtica "karstificación". El citado fenómeno se puede observar en algunas fuentes del Paseo del Prado (foto 9). La solubilidad del carbonato viene condicionada por la siguiente reacción química:

$$
\mathrm{H}_{2} \mathrm{O}+\mathrm{CO}_{2}+\mathrm{CO}_{3} \mathrm{Ca}_{\text {(Insoluble })}=\left(\mathrm{CO}_{3} \mathrm{H}\right)_{2} \mathrm{Ca}_{\text {(SOluble) }}
$$

Un incremento en el $\mathrm{CO}_{2}$, desplaza la reacción a la derecha y la roca se disuelve con mayor facilidad, por eso las calefacciones, emisiones de los tubos de escape de los vehículos y diversos humos industriales, aumentan los contenidos de anhídrido carbónico, que disuelto en el agua de lluvia actúa sobre el carbonato, contribuyendo eficazmente a la destrucción de la piedra monumental en las zonas urbanas e industriales.

Hay una serie de factores que controlan los contenidos de $\mathrm{CO}_{2}$. El descenso de presión y el aumento de temperatura, provocan un decrecimiento en el contenido de dióxido de carbono en las aguas. Asimismo, un aumento de la alcalinidad se traduce en una menor solubilidad. En contraposición, el carácter ácido de la lluvia en algunas zonas indus- triales, en condiciones de presión y temperatura favorables, puede crear graves problemas en la cohesión de los elementos pétreos externos.

Siendo el agua absorbida la responsable de la disolución de los materiales, la configuración del sistema poroso y la composición de la roca son factores cuyo estudio es de gran importancia. En las zonas más externas, en cambio, los procesos de evaporación aumentan la concentración salina, depositándose una costra carbonatada que va a ir sellando los conductos capilares e impermeabilizando la roca, con lo que se logra una mayor protección de la misma. Si existen sales solubles, por el contrario, se pueden formar criptoeflorescencias que contribuyen poderosamente a la destrucción del material.

Cuando el agua de lluvia presenta contenidos de $\mathrm{H}_{2} \mathrm{SO}_{4}$, procedente de los gases $\mathrm{SO}_{2}$ y $\mathrm{SO}_{3}$ derivados de la actividad industrial, vehículos de motor y calefacciones de carbón, con pirita, y fuel, se forma yeso de acuerdo con la siguiente reacción:

$$
\mathrm{SO}_{4} \mathrm{H}_{2}+\mathrm{H}_{2} \mathrm{O}+\mathrm{CO}_{3} \mathrm{Ca}=\mathrm{SO}_{4} \mathrm{Ca} \cdot 2 \mathrm{H}_{2} \mathrm{O}+\mathrm{CO}_{2}
$$

Este yeso se deposita en las zonas más externas de las rocas. Debido a su carácter relativamente soluble, si la deposición se produce en una zona susceptible de sufrir la acción continuada de la lluvia, en lugares donde ésta sea abundante, se produce un lavado de las sales precipitadas, pero si consideramos otras partes del edificio más resguardadas, es probable que el yeso permanezca. En cambio, en zonas de climas áridos, las costras de yeso formadas alcanzan un cierto espesor.

Los óxidos nitrosos, son otro producto de la acción contaminante de los ambientes urbano-industriales donde estos gases procedentes de los motores de combustión se agrega al originado en las tormentas por oxidación del nitrógeno atmosférico. Su acción, similarmente al caso anterior, es la acidificación de las aguas de lluvia y el ataque a la piedra carbonatada.

Los cloruros, muy característicos de los ambientes marinos, son depositados en la piedra mediante aerosoles. Estas sales son muy solubles y con gran capacidad de destrucción generando procesos de alveolización y arenización.

En el caso de las dolomitas, el contenido en magnesio de la roca, puede llevar a la formación de epsomita, parcialmente responsable de la degradación de la misma. La presencia de arcillas expansivas en calcarenitas (pellets de glauconita) producen efectos idénticos a los descritos en las areniscas, tal como se puede comprobar, por ejemplo, con las rocas del Mioceno Superior Marino de la región levantina, muy utilizadas en la construcción y en la restauración monumental durante este siglo. Los 
ciclos humedad-sequedad son el origen de cambios volumétricos en las esmectitas, ocasionando esfuerzos sobre la roca de la que son constituyentes.

Al ser las rocas carbonatadas portadoras, en algunos casos, de pequeñas cantidades de minerales metálicos sulfurados y de óxidos, se pueden hacer aquí las mismas consideraciones sobre coloración que se han efectuado en el caso de las areniscas.

Aunque dependiendo del clima, y dada la composición de las rocas carbonatadas, los agentes químicos son normalmente los máximos responsables de la alteración; también existen otros factores a tener en cuenta, tales como las heladas y la acción del viento. Esta última es más activa para las areniscas al encontrarse generalmente constituidas por elementos heterogeneos. Asimismo, es bien conocido que la oxidación de los anclajes de hierro conlleva un aumento de volumen que origina fuertes tensiones sobre la piedra, colaborando eficazmente a la destrucción de ésta en sus inmediaciones.

\section{CONSIDERACIONES FINALES}

En los numerosos monumentos y construcciones existentes en nuestro país, se encuentra una gran variedad de rocas, en cuanto se refiere a litologías y edades de formación. En consecuencia, son necesarios conocimientos mineralógicos y geológicos para abordar su identificación así como la de los procesos de degradación que les afecten.
Según D. ANTONIO MAS GUINDAL (responsable del Dpto. de Monumentos y Arqueología del Ministerio de Cultura; citado por ECIJA, I. G. en rev. MUFACE):

"La ciencia de la tecnología del Patrimonio es una ciencia móvil, hay momentos en la historia en los que se ha actuado sin un conocimiento concreto y sin incorporar los profesionales adecuados, quizá por que no los había...".

En la actualidad, no aparece elaborada una tecnología precisa de cómo operar, sin embargo, cada vez existe una mayor conciencia de la necesidad de conocer siquiera someramente el material con que se va a restaurar y de diagnosticar el proceso que se encuentra sufriendo. Siendo cada monumento un ente único y contingente, no existen unas reglas del arte inmutables y de aplicación universal; el restaurador se enfrenta cada vez con un problema singular, y tiene que asumir la responsabilidad de la actuación que se acometa. Sin embargo, no debería abordar una obra de esta naturaleza sin conocer los parámetros del problema para lo que requiere el apoyo y la asistencia de un equipo técnico.

Resumiendo lo anterior, el conocimiento de los materiales constituye el paso previo al diagnóstico de las patologías y la elección de los métodos de tratamiento posterior. En este orden, sería de suma utilidad encontrar referenciadas en la bibliografía las características más importantes de las rocas utilizadas en la construcción. El presente trabajo constituye un paso en este sentido.

\section{BIBLIOGRAFIA}

ALCALDE, M. y MARTIN, A. (1988). Macroscopical study of the stone alteration I. The Catedral de Sevilla. VI Congrés intern. sur l'alteration et la conservation de la pierre. pp. 217-225. Torún (Polonia).

ALBARAN, E. (1990). La Cibeles y Neptuno vinieron de Montesclaros. Madrid.

ALONSO, F. J. (1986). Caracterización petrofísica y alterabilidad de calizas y dolomías. Tes. doc. Univ. Oviedo. 309 pp.

CABRERA, J. M. (1973). Alteración y conservación de materiales pétreos en monumentos. Tes. doc. Univ. Autónoma de Madrid.

CABRERA, J. M. (1987). Conservación y Restauración. El patrimonio cultural de Castilla y León. Ed. Junta de Castilla y León. Consejería de Cultura, $15 \mathrm{pp}$.

DE LA PLAZA, F. J. Investigaciones sobre el Palacio Real Nuevo de Madrid. pp 66-81 y 366-367.

ECIJA, I. G. (1990). Un plan para recuperar las catedrales. El Mal de la Piedra. Rev. Muface, marzo 1990, pp. 18-20.

ESBERT, R. M. y ORDAZ, J. (1985). Alteración y alterabilidad de las piedras de construcción: criterios petrofisicos y ensayos de laboratorio. I Congrés de Patología a l'Edificacio. Col. Arquit. Cataluña. Barcelona. 
ESBERT, R. M. y VALDEON, L. (1985). Alterabilidad de areniscas asturianas utilizadas en monumentos. Bol. Geol. Min. TXCVI-VI, pp. 659-666.

ESBERT, R. M. y al. (1989). Petrografía, propiedades físicas y durabilidad de algunas rocas utilizadas en el Patrimonio Monumental de Cataluña, España. Mat. Contr. V. 39, n. ${ }^{2} 214$, abril-mayo-junio-89, pp. 37-47.

GARCIA DE MIGUEL, J. M. y al. (1990). Estudio petrológico previo a la restauración de la fachada de la Antigua Universidad de Alcalá de Henares. I Jornadas sobre el Tratamiento de la Piedra en Monumentos y en la Construcción. 31 pp.

GARCIA DE MIGUEL y SANCHEZ CASTILLO, L. (1989). El papel del técnico en la conservación y restauración. Roc Máquina, 3T, 89, pp. 15-20.

GUTIERREZ MARCOS, J. y BUSTOS, C. (1989). Madrid restaura en Comunidad. Ed. Consejería de Cultura de la C.A.M., 58 pp.

HERNANDEZ PACHECO, F. (1954). Materiales litológicos del territorio de Madrid empleados en la construcción. Las Ciencias, $1: 800.000$ Madrid.

IÑIGUEZ, J. (1961). Alteración de calizas y areniscas como materiales de construcción. Tes. Doc. Univ. Complutense de Madrid. Publicación Ministerio de Educ. Nacional. Dirección Gen. de Bellas Artes. 131 pp.

LOPEZ AZCONA, C. (1990). Metodología de la restauración de la Catedral de Toledo. I Jornadas sobre tratamiento de la Piedra en los Monumentos y en la Construcción. ETS de Ing. de Minas. Madrid. 17 pp.

MARTIN GARCIA, J. C. y MARTIN GARCIA, M. A. (1966). Apuntes de Geología. Ed. ETS de Ing. de Caminos, Canales y Puertos, $278 \mathrm{pp}$.

MAZARRASA, O. y FERNANDEZ HERRERO, F. (1988). Mazarrasa Maestros canteros y arquitectos de Trasmiera. Ed. Col. Of. Arquit. de Cantabria. $284 \mathrm{pp}$.

ORDAZ, J. (1983). Características físicas y alterabilidad de la piedra de Villamayor (Salamanca). Materiales de Construcción, 190191 pp. $85-95$

PLINIO EL VIEJO (1981). Histoire Naturelle. Libro XXXVI. Traducido por BLOCH, R. y comentado por ROUVERET, A. Ed. Les Belles Letres. París.

REPULLES, E. M. (1916). La nueva Catedral de Ntra. Sra. de la Almudena de Madrid. Memoria realizada por ericargo de la junta de obras, $28 \mathrm{pp}$.

\title{
publicación del ICCET/CSIC
}

\author{
ACUEDUCTOS ROMANOS EN ESPAÑA \\ Carlos Fernández Casado
}

Prof. Dr. Ing. de Caminos, Canales y Puertos

Esta publicación se compone de una serie de artículos, publicados en la Revista "Informes de la Construcción", en los cuales se hace un análisis de los acueductos romanos que existen en España y el balance de las condiciones de conservación en que se encuentra cada uno de ellos, incluyendo referencias históricas y literarias.

Se ha ilustrado con la reproducción de la valiosa documentación gráfica que posee el prestigioso autor.

Un volumen encuadernado en couché, a dos colores, de $21 \times 27$ centimetros, compuesto de 238 páginas, numerosos grabados, dibujos, fotos en blanco y negro y figuras de línea.

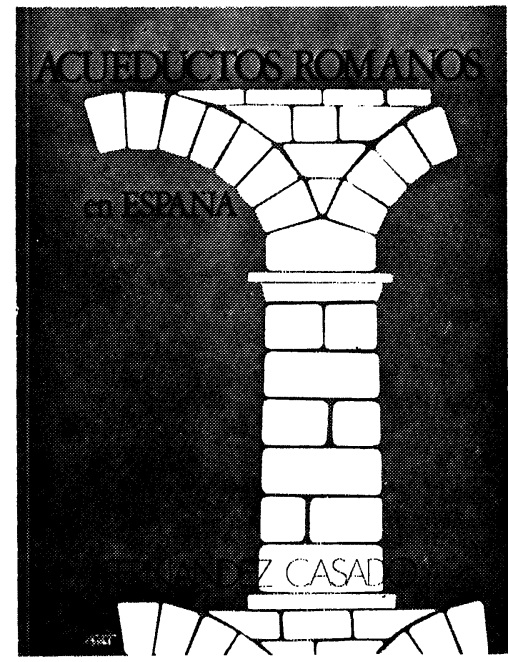

